\title{
En 59 år gammel mann med ryggsmerter etter mulig hypoglykemisk krampeanfall
}

\author{
Hypoglykemi kan gi bevisstløshet og kramper. I dette tilfellet ble \\ mannen innlagt i medisinsk avdeling, men ble overført til intensivavde- \\ lingen som ortopedisk pasient med omfattende bekkenskader.
}

Se kommentar side 1155 og kunnskapsprøve på www.tidsskriftet.no/quiz

\section{Cecilie Bendiksen \\ cbendiksen75@hotmail.com \\ Abbas Emami \\ Ortopedisk avdeling \\ Jan Prytz \\ Radiologisk avdeling \\ Hedda Soløy-Nilsen \\ Enhet for patologi \\ Diagnostisk klinikk \\ Erik Waage Nielsen \\ Akuttmedisinsk avdeling \\ Nordlandssykehuset Bodø \\ 8092 Bodø}

Pasienten var 59 år. Han hadde alkoholbetinget leversvikt og insulinkrevende diabetes mellitus type 2. Han var i relativt god form, og fastlegen hadde ikke opplysninger om annen sykdom.

Hele den aktuelle dagen hadde han vært sammen med sin mor for å kjøre henne i forskjellige ærender. Da han begynte å merke symptomer på hypoglykemi, stoppet de utenfor nærmeste kiosk slik at moren kunne løpe inn for å kjøpe sjokolade. Da hun kom tilbake til bilen etter 1-2 minutter, fant hun sønnen bevisstløs i førersetet. Kroppen hvilte mot bildøren og sidevinduet. Siden hun ikke fikk kontakt med ham, ringte hun 113. Ambulansen var på stedet etter to minutter. Det var ingen andre vitner til hendelsen.

Ambulansepersonalet observerte at mannen fortsatt satt i førersetet på bilen. Det var ingen tegn til ytre skade verken på bil eller pasient. Det rant litt blod ut av den ene munnviken hans. Det viste seg at dette skyldtes en bittskade $i$ tungen. Han åpnet øynene på kommando, men var forvirret og hadde snøvlete og uforståelig tale. Respirasjonsraten var normal. Huden var klam og kald. Blodtrykk og puls var ikke oppgitt. Ambulansepersonellet målte blodglukosenivået til 2,4 mmol/l.

De antok at mannens tilstand skyldtes hypoglykemi.
Det ble lagt inn venekateter og gitt $40 \mathrm{ml}$ $50 \%$ glukose intravenøst. Deretter viste ny blodsukkermåling 8,6 mmol/l. Pasientens mentale status ble gradvis bedre, men han klaget over smerter nederst i ryggen. Han ankom sykehuset $i$ ambulanse 52 minutter etter anfallsdebut - på vanlig båre.

Pasienten ble innlagt i medisinsk avdeling med diagnosen hypoglykemi. Ved innkomst ble det etablert ytterligere én intravenøs tilgang. Han fikk morfin intravenøst $2,5 \mathrm{mg}$ mot kraftige ryggsmerter. Dette hadde god effekt. Blodtrykket etter innkomst var 69/47 $\mathrm{mm} \mathrm{Hg}$ (middeltrykk $54 \mathrm{~mm} \mathrm{Hg}$ ). Pulsen var 100 per minutt og regelmessig. Glasgow Coma Scale var normal (skår 15). Blodglukosenivået var 10,6 mmol/l og Hb var 13,2 g/ $100 \mathrm{ml}$. EKG viste normal sinusrytme. Huden var blek, tørr og kald.

Siden lavt blodtrykk er listet som en bivirkning av morfin, antok helsepersonellet at det lave blodtrykket var forårsaket av morfinet, som var gitt intravenøst.

Det ble gitt nalokson og Ringer-acetat 400 $\mathrm{ml} / \mathrm{t}$ som volumerstatning. Behandlingen hadde ingen effekt på blodtrykket. Pasienten fortsatte å klage over ryggsmerter. Ved undersøkelse kunne han bevege begge beina, men enhver bevegelse gjorde ryggsmertene verre.

Indremedisinerne lurte på om det kunne være en annen cerebral årsak til bevissthetstapet enn hypoglykemi. De ba også om nevrologisk tilsyn for å vurdere ryggsmertene. Man diskuterte også om hypotensjonen og ryggsmertene kunne skyldes et abdominalt aortaaneurisme med disseksjon eller begynnende lekkasje. Pasienten ble derfor henvist til CT-undersøkelse av hodet, abdomen og bekken.

CT-undersøkelsene, som ble gjort omtrent to timer etter innkomst, avkreftet aortaaneurisme og alvorlig sykdom i hodet. Det var basale fortetninger $i$ begge lunger. CTundersøkelse av bekkenet viste multiple frakturer (fig 1, fig 2). På høyre side var det knusing av massa lateralis sacrii og en fraktur av fremre bekkenring med flere små fragmenter. På venstre side var femur trykt inn i bekkenet med en knusingsfraktur iacetabulum. Det var væske retroperitonealt og $i$ muskulaturen i bekkenet. Mengden kunne ikke angis eksakt. På grunn av pasientens fallende blodtrykk og økende puls ble det startet kontinuerlig infusjon med noradrenalin i tillegg til pågående væskeinfusjon.

Ved ny klinisk undersøkelse viste det seg at smertene var lokalisert mer til bekkenregionen enn til ryggen. Pasienten var hemodynamisk ustabil, bekkenfrakturen var ustabil, og i tillegg var det acetabularfraktur. Bekkenfrakturen var den sannsynlige blødningskilde. Ortopedene bestemte seg derfor for å stabilisere frakturene med ekstern fiksasjon.

Bekkenvolumet øker ofte ved ustabil bekkenfraktur. Ved å reponere, minske volumet og stabilisere bekkenet med ekstern fiksasjon skaffer man bedre forutsetninger for hemostase.

INR-verdien ble første gang målt før operasjonen og var 2,0. Spontant forhøyet INRverdi var sannsynlig betinget $i$ pasientens kjente leversvikt. Under operasjonen 6,5 timer etter skaden var det påfallende blødning fra beinmargen i crista iliaca da de eksterne fiksasjonspinnene ble satt inn. Dette ble sett på som et tegn på nedsatt koagulasjonsevne, og var således en dårlig prognostisk faktor. Inngrepet tok 100 minutter. I løpet av tiden på operasjonsstuen ble det gitt tre enheter blod. Pasienten ble lagt på intensivavdelingen for overvåking gjennom natten.

Parallelt lette legene etter en samlende forklaring på pasientens symptomer, hypoglykemiske kramper og alvorlige bekkenfrakturer. Ved å søke på symptomene i Google var det mange treff, som igjen ledet til flere artikler i PubMed om kramper som årsak til en rekke frakturtyper. Man trodde nå at bekkenfrakturene skyldtes et krampeanfall i bilen.

Bedømt ut fra rapporten fra intensivavdelingen oppfattet ortopedene at pasientens tilstand så ut til å stabilisere seg. Det ble gjort avtale mellom intensivavdelingen og ortopedene om at vakthavende ortopeder skulle ha beskjed hvis tilstanden ikke utviklet seg tilfredsstillende utover natten. 


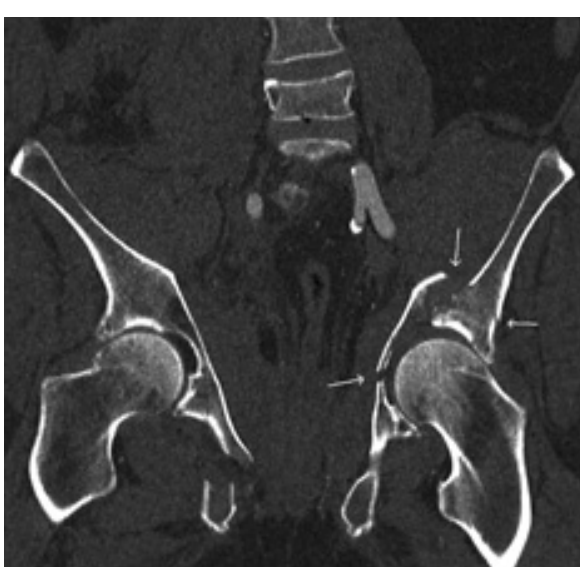

Figur 1 Knusingsfraktur av venstre acetabulum (piler), hvor femur er trykt inn i bekkenet. Frakturer i fremre bekkenring ses også

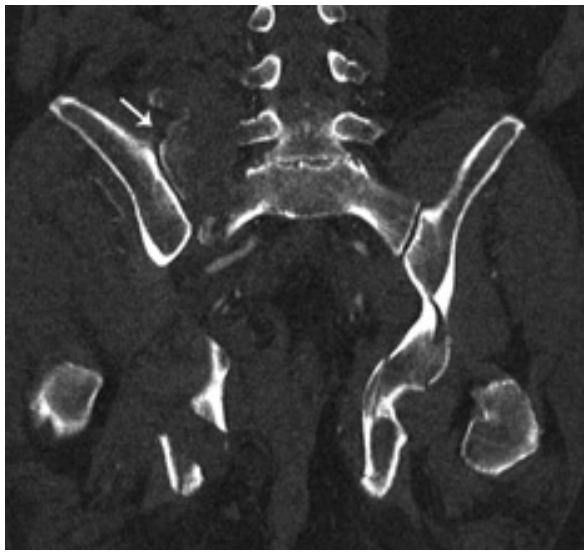

Figur 2 På høyre side er det en knusing av massa lateralis sacrii (pil). I tillegg ses fraktur av fremre bekkenring med flere fragmenter

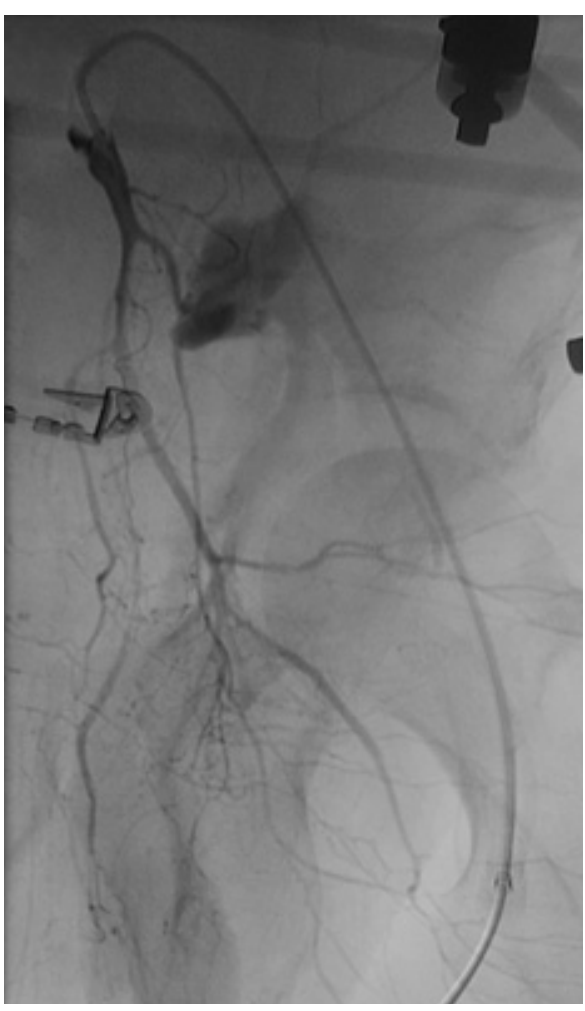

Figur 3 Angiografi viste rikelig blødning fra en gren av venstre a. iliaca interna
I løpet av natten fikk pasienten til sammen 7 l Ringer-acetat. I tillegg fikk han fem enheter blod, to enheter Octaplas, $1 \mathrm{~g}$ Cyclokapron, $20 \mu \mathrm{g}$ Octostim og $400 \mathrm{ml}$ trombocyttkonsentrat. Blodtrykket var $100 / 40 \mathrm{~mm} \mathrm{Hg}$ (middeltrykk $60 \mathrm{~mm} \mathrm{Hg}$ ) og pulsen 95-100 slag per minutt. Hb var 7,6 g/100 ml, trombocytter $63 \cdot 10^{9}$ /l. INR-nivået var 3,3.

Ortopedene oppfattet nå pasientens tilstand som vedvarende hemodynamisk ustabil - til tross for stabilisering av bekkenet med ekstern fiksasjon. Begynnende nyresvikt og progredierende forverring av koagulasjonsevnen bidro til at situasjonen ble ansett å være kritisk. Videre behandlingsmuligheter ble drøftet mellom ortopeder og kirurger. Alternativer var bekkenpakking eller angiografi med embolisering. Gastrokirurgene var skeptiske til å gjøre bekkenpakking fordi de antok det ville innebære stor risiko for pasientens liv.

Etter konferering med radiolog ble det bestemt at man skulle utføre angiografi med embolisering. Angiografi (fig 3) viste blødning fra en tynn gren fra høyre a. iliaca interna samt fra en lumbalarterie på høyre side. Det ble utført embolisering med flere metallspiraler $i$ sidegrener samt $i$ hovedstammen til høyre a. iliaca interna. Deretter ble det satt flere små metallspiraler i lumbalarterien på høyre side. Til slutt ble en bakre gren fra venstre a. iliaca interna embolisert, der det var tydelig kontrastovergang til bekkenhematomet. Kontrollserier med kontrastinjeksjon gjennom føringskateter på de aktuelle stedene viste opphevet eller sterkt redusert blodstrøm. Radiologen forventet full trombosering i løpet av kort tid.

Behandlende leger drøftet om hjertesykdom kunne være en tilleggsårsak til hypotensjonen og om avløpshinder kunne forklare nedsatt urinproduksjon.

Ekkodopplerundersøkelse av hjertet viste dårlig fylling, som ved hypovolemi, og normal ejeksjonsfraksjon på $75 \%$. Det var ingen perikardvæske. Venstre ventrikkel var hypertrof. Ultralydundersøkelse av abdomen og urinveier viste ikke tegn til postrenal obstruksjon.

Emboliseringen bedret ikke situasjonen. Blodtrykket sank og pasienten ble bradykard. Han døde ca. 36 timer etter anfallet.

Postmortal beintetthetsmåling ble gjort. Tettheten (BMD) var 1,133 $\mathrm{g} / \mathrm{cm}^{2}, T$-skàr 0,7. Ut fra WHO-kriterier er dette normal beintetthet for alderen. Obduksjonen viste ingen ytre tegn til vold eller skade. Det var store mengder koagulert blod i bekkenet, og det sto beinsplinter opp i bløtvevet flere steder i det lille bekkenet. Biopsier fra brudd i bekkenet viste upåfallende beintrabekler med blødning, som ved fraktur. Det var ingen tegn til traumatisk ødeleggelse av parenkymatøse organer. Leveren var forstørret, med lite bevart arkitektur. Det var uttalt fettinfiltrasjon og fibrose.

\section{Diskusjon}

De problemene som oppsto underveis i behandlingsforløpet hos denne pasienten, har gitt oss nyttige erfaringer som vi vil gjennomgå i det følgende. Vi har sett at det mulige krampeanfallet kan ha forårsaket den fysiske skaden, og vi har erfart at dårlig kommunikasjon mellom helsepersonell kan forsinke potensielt livreddende behandling. En annen erfaring er at pressor brukt til pasient med blødning kan maskere hvor alvorlig tilstanden egentlig er.

Bekkenringen har en solid oppbygging som består av beinete strukturer, sterke ligamenter og et stort antall arterier og vener. Bekkenfraktur er derfor en alvorlig skade som i verste fall kan medføre blødningssjokk og død. De fleste pasienter med alvorlig bekkenfraktur har vært utsatt for høyenergitraume i form av trafikkulykke eller fall fra stor høyde. Bekkenfrakturen er da sjelden eneste skade (1). Siden det ikke forelå noe kjent traume hos vår pasient, tenkte vi ikke på muligheten av at det her kunne foreligge bekkenskade.

Vi vet at pasienter med epilepsi har høyere frekvens av frakturer enn normalbefolkningen, og det er tidligere beskrevet flere tilfeller av bekkenfraktur etter krampeanfall $(2-5)$. Frakturen er da oftest ensidig eller dobbeltsidig sentral acetabularfraktur. I de fleste tidligere beskrevne tilfeller har pasienten fătt fraktur i forbindelse med epileptiske generaliserte tonisk-kloniske anfall uten eller med minimalt falltraume, som for eksempel fall fra seng (2-5). I de tilfellene hvor krampeanfallet ikke var av epileptisk natur, er eklampsi, nyresvikt, encefalitt, hyponatremi og elektrokonvulsiv behandling rapportert som utløsende faktorer $(2,4)$. Når det gjelder vår pasient, er det ingen som har observert noe krampeanfall. Vi mener dog at hypoglykemi, tap av bevissthet, tungebitt og bekkenfraktur i fravær av tegn til ytre skade gjør det overveiende sannsynlig at han hadde gjennomgått et hypoglykemisk krampeanfall.

Bekkenfraktur etter hypoglykemiske kramper er så vidt vi vet ikke tidligere beskrevet. Vår pasient hadde en svært omfattende og potensielt dødelig bekkenskade. Dette er heller ikke tidligere beskrevet i forbindelse med kramper.

I tilfeller med krampeanfall uten annet traume er det sannsynligvis muskelkontraksjonene under krampeanfallet som er kraftige nok til å gi frakturer - også hos personer med normal beinkvalitet. Det er derfor et svært viktig poeng at alle pasienter som kan ha gjennomgått krampeanfall undersøkes nøye klinisk, og at det er lav terskel for røntgenundersøkelse ved smerter.

Kommunikasjonen mellom ulike faggrupper er viktig, også i behandling av bekkenskade. En alvorlig bekkenskade kan forårsa- 
ke arteriell blødning i bekkenet. Reponering og stabilisering av bekkenet er alltid første skritt i behandlingen. Dette er effektivt ved venøse bekkenblødninger (foreligger i $90 \%$ av tilfellene), men ved arteriell bekkenblødning vil det ofte være nødvendig å gå videre med bekkenpakking eller embolisering. Det er en stor fordel om denne behandlingen iverksettes uten unødig forsinkelse.

I vårt tilfelle ser vi at dårlig kommunikasjon og mangel på klare retningslinjer forsinket behandlingsforløpet. Begrepet «hemodynamisk instabilitet» ble mye brukt i diskusjoner rundt pasienten. Vi fikk erfare at begrepet tolkes forskjellig av ulike faggrupper. Det er derfor dårlig egnet som styringsverktøy. Det er viktig å ha utvetydige kriterier for vurdering, slik at alle som er involvert $\mathrm{i}$ behandlingen av en kritisk syk pasient $i$ tide innser hvor alvorlig tilstanden er.

Ifølge Ullevåls traumemanual (6) er det indikasjon for angiografi og eventuelt embolisering ved et transfusjonsbehov på mer enn seks enheter blod i løpet av det første døgnet, eller fire enheter eller mer per 24 timer senere i forløpet.

Miller og medarbeidere (7) definerer en pasient med bekkenfraktur som hemodynamisk ustabil dersom det systoliske blodtrykk er $<90 \mathrm{~mm} \mathrm{Hg}$ på tross av transfusjon av $2000 \mathrm{ml}$ krystalloider eller to enheter blod. Vår pasient var hemodynamisk ustabil etter både traumemanualen (6) og Miller og medarbeideres (7) kriterier. Dersom vi hadde brukt slike retningslinjer heller enn begrepet «hemodynamisk stabilitet», ville emboliseringen ha vært iverksatt tidligere - og pasienten hadde da hatt et bedre utgangspunkt for at behandlingen skulle lykkes.

Et siste viktig punkt å belyse i denne sykehistorien er bruk av pressor, $i$ vårt tilfelle noradrenalin, til en pasient med pågående blødning. Vi ser at denne behandlingen bidro til å fremstille pasientens tilstand som mindre kritisk enn den egentlig var. Også dette forsinket tiden det tok før embolisering ble iverksatt. Noradrenalininfusjon utsetter og maskerer blødningssjokk, men behandler ikke årsaken. Blødningssjokk skal derfor ikke behandles med noradrenalin.

Sammenfatningsvis kan vi slå fast at bekkenskade kan være en komplisert tilstand. Dersom man befinner seg i et sykehus uten bekkenkirurgisk ekspertise, er det viktig raskt å opprette kontakt med et senter for bekkenkirurgi. Da kan man få råd om initial behandling og eventuelt planlegge overflytting av pasienten uten unødig forsinkelse.
Oppgitte interessekonflikter: Ingen

Pasientens pårørende har gitt samtykke til at artikkelen blir publisert.

\section{Litteratur}

1. ATLS Student course manual. 8. utg. Chicago, IL: American College of Surgeons Committee on Trauma, 2008.

2. Duus BR. Fractures caused by epileptic seizures and epileptic osteomalacia. Injury 1986; 17: $31-3$

3. Hertlein H, Mittlmeier T, Schürmann M et al. 2Pfeiler-Acetabulumfraktur mit zentraler Hüftluxation und ipsilaterale Schenkelhalsfraktur beim epileptischen Anfall. Chirurg 1991; 62: 429-31.

4. Granhed HP, Karladani A. Bilateral acetabular fracture as a result of epileptic seizure: a report of two cases. Injury 1997: 28: 65-8.

5. Sikkink C, van der Tol A. Unilateral transverse acetabular fracture with medial displacement of the femoral head after an epileptic seizure. J Trauma 2000: 48: 777-8.

6. Traumemanual Ullevål universitetssykehus. www.ulleval.no/stream_file.asp?iEntityld =21162 (18.2.2010)

7. Miller PR, Moore PS, Mansell E et al. External fixation or arteriogram in bleeding pelvic fracture: initial therapy guided by markers of arterial hemorrhage. J Trauma 2003; 54: 437-43.

Manuskriptet ble mottatt 15.4. 2009 og godkjent 18.2. 2010. Medisinsk redaktør Are Brean

\section{Kommentar}

\section{Skader etter krampeanfall}

Anfallsrelaterte skader er en av epilepsiens mange og kjedelige komplikasjoner. Epileptiske anfall kan gi direkte skader som følge av sterke muskelkontraksjoner under generaliserte toniske eller tonisk-kloniske anfall, eller føre til indirekte skader som følge av fall eller ulykker forårsaket av anfallet.

En europeisk multisenterstudie viste at $25 \%$ av alle uhell hos epilepsipasienter var anfallsrelaterte. De vanligste følgene var hodeskader, sårskader, brudd og hudavskrapninger - i den rekkefølgen (1). Nakken \& Lossius rapporterte at $32 \%$ av multifunksjonshemmede pasienter med epilepsi opplevde anfallsrelaterte skader i løpet av 13 måneder (2).

Mange anfallsrelaterte skader er det vanskelig å beskytte seg mot, men av og til kan enkle tiltak virke forebyggende. Eksempelvis kan sengehest hindre fall ut av sengen, brannskader kan unngås hvis sengen ikke står inn mot panelovn og komfyren kan utstyres med sikring. En fallalarm med GPS kan fange opp fall i forbindelse med anfall og angi hvor vedkommende befinner seg.

De anfallstyper som erfaringsmessig hyppigst gir skader, er de som er ledsaget av henholdsvis tilstivning og plutselig tonustap. Slike anfall fører ofte til stygge hode- og ansiktsskader. Hjelm, ev. forsterket pannebånd, kan gi noe beskyttelse. Bruddskader er ikke uvanlig i epilepsipopulasjonen, og vertebrale kompresjonsfrakturer som følge av tonisk-kloniske anfall blir ofte oversett. Osteopene effekter av enkelte antiepileptika øker risikoen for anfallsrelaterte brudd (3).

Bendiksen og medarbeidere gir en god beskrivelse av en pasient med diabetes og alkoholbetinget leversvikt. Han ble funnet bevisstløs - med hypoglykemi, tungebitt og store bekkenskader. Selv om det ikke var noen vitner til det som skjedde, er det trolig riktig at pasienten hadde hatt et generalisert tonisk-klonisk anfall, slik forfatterne antar. Han døde ca. 36 timer etter det antatte krampeanfallet på grunn av blødninger i bekkenet.

Brudd i hofter og bekken er flere ganger beskrevet som følge av krampeanfall (4). Blant annet var dette en fryktet komplikasjon til ECT-behandling på den tiden man ga slik behandling uten narkose (4). Det er også tidligere rapportert om hoftefraktur som følge av krampeanfall med dødelig utgang pga. bekkenblødning (5).

Kasuistikken minner oss om hvilke sterke krefter det kan være i forbindelse med epileptiske anfall, og at det bør være lav terskel for å rekvirere røntgenundersøkelse av pasienter som etter krampeanfall - uansett av hvilken årsak - gir uttrykk for smerter.

\section{Morten Ingvar Lossius}

morten.lossius@epilepsy.no

Avdeling for kompleks epilepsi (SSE)

Klinikk for kirurgi og nevrofag

Oslo universitetssykehus

Postboks 53

1306 Bærum postterminal

Oppgitte interessekonflikter: Ingen

\section{Litteratur}

1. Beghi E, Cornaggia C, The RESt-1 group. Morbidity and accidents in patients with epilepsy: results of a European cohort study. Epilepsia 2002; 43: $1076-83$

2. Nakken KO, Lossius R. Seizure-related injuries in multihandicapped patients with therapy-resistant epilepsy. Epilepsia 1993: 34: 836-40.

3. Nakken KO, Taubøll E. Bone loss associated with use of antiepileptic drugs. Expert Opin Drug Saf 2010; e-publisert 4.3.2010.

4. Wirrell EC. Epilepsy-related injuries. Epilepsia 2006: 47: 79-86.

5. Hughes CA, O'Briain DS. Sudden death from pelvic hemorrhage after bilateral central fracture dislocations of the hip due to an epileptic seizure. Am J Forensic Med Pathol 2000; 21: 380-4. 